\title{
Chinese Improved National Instruments — Plucked Stringed Musical Instruments
}

\author{
Ha Neul Lee ${ }^{1}$ Yiyi Zhang,"*
}

\author{
${ }^{1}$ Music Department, Seoul National University, Seoul 08826, Korea \\ ${ }^{2}$ Music Department, Moscow State Pedagogical University, Moscow 119435, Russia \\ ${ }^{*}$ Corresponding author. Email: yiyi1999@yandex.ru
}

\begin{abstract}
The plucked stringed instrument is a very distinctive type of string instrument among Chinese national musical instruments. This paper analyzes the classification of Chinese national plucked stringed musical instruments, and takes pipa (琵琶), ruan (阮), liuqin (柳琴), and zheng (筝) as examples to analyze the current status of the improvement and development of Chinese traditional national musical instruments. Several improvement principles are proposed, including retaining national elements, conforming to national aesthetics, maintaining national charm, and combining art and science.
\end{abstract}

Keywords: improved national musical instruments, plucked stringed musical instruments, pipa, ruan, liuqin, zheng

\section{INTRODUCTION}

The Chinese nation has a wealth of accomplishments in all aspects during the history of five thousand years. As far back as the Zhou Dynasty, more than three thousand years ago, plucked stringed musical instruments such as qin (琴) and se (瑟) appeared. With the change of dynasties and the integration of nationalities, all kinds of musical instruments blossomed together. To study the development of Chinese improved national plucked stringed musical instruments, it's necessary to firstly understand the types of national plucked stringed musical instruments.

\section{Classification of Chinese national PLUCKED STRINGED MUSICAL INSTRUMENTS}

Plucked stringed musical instruments are a general term for a class of string musical instruments, which mainly refer to musical instruments whose sound is made by plucking strings with fingers or plucking and striking strings with bamboo hammer. According to the position of the performance, it is divided into horizontal and vertical styles, horizontal styles such as guzheng (古 筝), guqin (古琴) and dulcimer; vertical styles such as pipa, liuqin, konghou (管篌) and dombra (冬不拉).

According to the difference in form, performance and playing method, it is mainly divided into three categories:
- The body of the instrument is a rectangular wooden box with strings on it, which can be laid flat when being played. Such as musical instruments of qin and zheng

- The body of the instrument has different shapes, with two, three or four strings held and played vertically. During the performance, the player presses the strings with the left hand and plucks the strings with the right hand. Such as pipa, ruan, sanxian (三弦) and liuqin, etc.

- The dulcimer imported from foreign countries becomes its own category. When playing, it is necessary for the player to hit the dulcimer flat on the wooden frame with the bamboo hammer to obtain the sound.

\section{THE MAIN IMPROVEMENT \\ ACHIEVEMENTS OF THE NATIONAL PLUCKED STRINGED MUSICAL INSTRUMENTS}

This section will start with the introduction of traditional Chinese plucked stringed musical instruments and introduce the improvement of the main Chinese plucked stringed musical instruments so far. It mainly introduces pipa, ruan, liuqin and zheng.

\section{A. Pipa}

As the first plucked stringed instrument, the pipa (also known as "枇杷") has a history of more than 3,000 years. The first appearance of the term "pipa" can be traced back to the Qin Dynasty. It is mainly made of 
wood or bamboo. Its sound box is semi-pear-shaped and equipped with four strings. In the past, silk strings were used to make strings. Nowadays, steel wire, steel rope, nylon and other materials are often used. There are "phases" and "frets" on the neck and bezel panel to determine the phoneme. According to the right hand technique of playing an instrument, it is divided into "pi" and "pa". The former refers to the right hand playing forward, and the latter refers to the right hand stirring backward. Before the Tang Dynasty, pipa was the general name for all the lute (also known as luteqin family) plucked stringed musical instruments in Chinese. So far, the unified shape of the pipa is a fourstring pipa with six phases and twenty-four frets. Its appearance is shown in "Fig. 1".

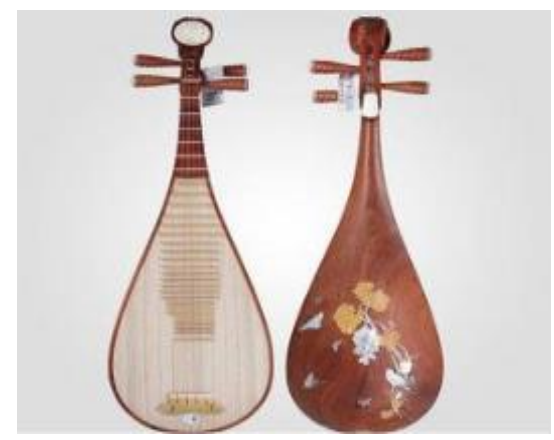

Fig. 1. Pipa.

Since modern times, ethnic musicians and instrument makers have made various improvements to the pipa, including the following ones:

1) Xiangpa (响琶): In the Chinese national orchestra, the sound of the pipa is so small that it can be easily covered up. Therefore, on the basis of the original pipa, Mr. Cheng Wujia from Nanjing University of the Arts designed, and Nanjing Xinghai National Musical Instrument Society made the xiangpa. The designer and producer modified the original backplane that only played the role of sound reflection. This modification made the backplane thinner and able to vibrate. In order to increase the volume of the pipa, the binded strings can be moved up and down, and the cello's C, G, d, a tuning method can be used. These changes make it strong penetrating power, and can be equal in volume with other musical instruments. Therefore, the pipa can participate in the large-scale national orchestral works of modern themes played by the national orchestra, but its popularity is not widespread.

2) Yиера (月琶): Yuepa is a new variety designed to meet the needs of Peking Opera accompaniment. It has the advantages of yueqin (月琴) and pipa. The producer is the same as the xiangpa, both designed by Mr. Cheng Wujia and produced by Xinghai National Musical Instrument Society. During production, the producer changed the thread to a bridge. The lower part of the resonance box is made similar to the yueqin. It can be tuned and played according to the traditional method of the pipa, and can also be tuned by violin and violin strings. The main tuning includes e, a, b, and e. Its sound is more sonorous and powerful than yueqin, its volume is louder, its tone quality is pure, its timbre is clear and melodious, and ull and translucent, and it is most suitable for cooperation with jinghu (京胡) as the accompaniment of Peking Opera.

3) High-pitched pipa: The high-pitched pipa was developed by Mr. Wu Guolong and Mr. Wen Bo from Beijing Song and Dance Ensemble. It has a crescentshaped upper right body, an open sound hole and a ventral surface of the sound window, and an adjustable inner sound column. The sound of a high-pitched pipa is one octave higher than that of an ordinary pipa, with balanced high and low sounds and a pleasant timbre.

4) Electric pipa: The electric pipa has rich expressive power, and it was developed jointly by Deng Wei, a pipa player of the Oriental Song and Dance Ensemble, and Tian Shuangkun, a string instrument producer from Beijing National Musical Instrument Factory. Its appearance has the national style of the original pipa, and the different part is that electrical components are installed on the bezel panel of the box. The principle of its sound is to install the pickup under the string close to the binded string, then use the principle of electromagnetic induction to convert the vibration of the string into an electrical signal, and finally produce sound through the sound amplification of the amplifier and the loudspeaker. Due to the resonance caused by such operation, and the reverberation caused by resonance, the thickness of the electric pipa bezel panel is increased, the volume of the resonance box is reduced, and the tone quality becomes more pure.

5) Crystal pipa: Zhao Cong, a contemporary Chinese pipa player, created the crystal pipa and has applied for a patent. The difference between the glass pipa and the ordinary pipa is that the glass pipa is made of high-grade glass and the loudspeaker is installed on the bezel panel. Its timbre is clear and bright, but the linger sound is not long.

\section{B. Ruan}

Ruan is short for ruanxian (阮咸). Ruanxian takes the name of Ruan Xian in the "seven sages of the bamboo grove" in the Western Jin Dynasty and evolved from pipa. Ruan Xian was said to be good at playing this kind of "pipa" and was also known as the "long-necked pipa". Ruan is composed of a circular resonance box and a straight handle. There are four strings and twelve columns of column loudspeaker. It is also a vertical 
plucked instrument. It is plucked with picks or artificial nails when being played, which has very rich expressive force. Since modern times, ruanxian musical instruments have undergone improvements, and have developed high-pitched ruan, low-pitched ruan, smallsized ruan, middle-sized ruan and large-sized ruan. The general structure of ruan musical instruments is shown in "Fig. 2".

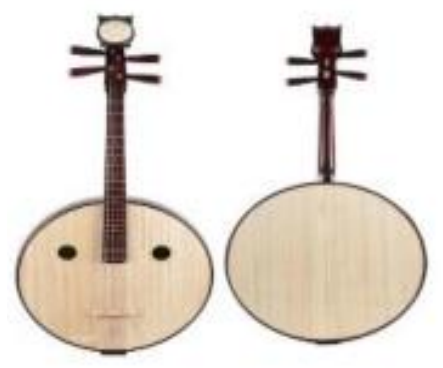

Fig. 2. Ruan.

This paper mainly introduces the improvement of middle-sized ruan in six strings, middle-sized ruan in double resonance box and middle-sized ruan in electric amplification.

1) Middle-sized ruan in six strings: In the 6th National Symposium on Musical musical instruments, the middle-sized ruan in six strings improved by the pipa maker Mr. Cao Weidong and the pipa player Mr. Wen Bo made an appearance at the conference, and it was called a revolutionary reform. The six-string design expands the range of middle-sized ruan, which makes it be able to play both the chords of Chinese folk music and the chords of the Western system.

2) Middle-sized ruan in double resonance box: The middle-sized ruan in double resonance box is made by Tianjin National Musical Instrument Factory. The box is enlarged and a thin resonance panel is added in the box near the back panel. The cavity is divided into two parts, the front and the rear. The width of the left and right frames of the box is reduced, so that the bezel panel and the back panel form a certain degree of camber. Its sound is mellow and thick, and the volume is significantly increased. But this design also makes it easy to reverberate when playing, especially when playing fast.

3) Middle-sized ruan in electric amplification: The middle-sized ruan in electric amplification is made by Shanghai No. 1 National Musical Instrument Factory. Similar to the production principle of the electric pipa, it has a high-fidelity pickup placed on the bezel panel near the binded string under the middle-sized ruan string. The pickup can effectively capture the vibration and rlinger sound of the strings and the resonance box, increasing the volume and amplifying the aftertaste of the sound while maintaining the traditional tone of middle-sized ruan.

\section{Liuqin}

At first, due to its simple structure and folk-like appearance, the Chinese folk called it "tupipa (土琵琶)", and it was also known as liuyeqin (柳叶琴) and King Kong leg. Its appearance, structure and playing method are similar to those of ruan, but liuqin has a pear-shaped box. The main structure is shown below ("Fig. 3").

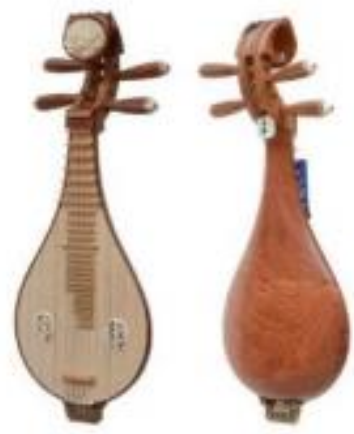

Fig. 3. Liuqin.

1) Three-stringed high-pitched liuqin: Mr. Wang Huiran of Jinan Military Region Qianwei Song and Dance Ensemble cooperated with Xuzhou National Musical Instrument Factory to produce a three-stringed twenty-four frets high-pitched liuqin in 1958. The backplane of the liuqin is made of high-quality mahogany, the bezel panel is made of high-quality sycamore wood, and the sound beam and action are installed in the abdominal cavity. Two round sound holes and bamboo products arranged in a twelve equal temperament chromatic scale are located on the bezel panel, inlaid with osseous or plastic sound windows. The silk string is made of steel wire or nylon wire, and the volume is increased. The tuning of the threestringed liuqin is based on the relationship of four and five degrees, set as d1, g1, d2 or d1, a1, d2, and there are three octaves from $\mathrm{d} 1$ to $\mathrm{d} 4$. The problem of modulation is solved, the range is slightly wider than the traditional liuqin, and the volume is slightly larger.

2) Four-stringed high-pitched liuqin: The fourstringed high-pitched liuqin is produced by Mr. Wang Huiran in cooperation with Xuzhou National Musical Instrument Factory. It is improved on the basis of the three-stringed high-pitched liuqin. It mainly adds a bass string and five high-pitched frets, which enriches the expressive force of the liuqin. Compared with the threestring, the tuning of the four-string is improved, the 
tuning is fixed, the range is expanded, and the phoneme is improved.

\section{Zheng}

The zheng has a history of more than two thousand years in China. It is also called guzheng and hanzheng ( 汉筝). It is also called qinzheng (秦筝) because it was popular in the Qin during the Warring States Period. It has a shape similar to a long box with a little protrusion in the middle, and it is generally made of sycamore wood. It has a flat or similar bottom panel, and its zheng foot on the head slowly fall. The zheng strings are set on the bezel panel of the wooden box body. The mazi (码子) is placed under each string, and the pitch and tone quality can be adjusted by moving left and right, and can be used for modulation. The traditional zheng's range is: $\mathrm{G} \sim \mathrm{c} 2$ for 13 -stringed zheng, $\mathrm{A} \sim \mathrm{a} 2$ for 16-stringed zheng, $\mathrm{A} \sim \mathrm{d} 3$ for 18-stringed zheng, $D$ $\sim \mathrm{d} 3$ for 21 -stringed zheng, and $\mathrm{G} \sim \mathrm{e} 3$ for 25 -stringed zheng. The 21-stringed zheng is commonly used today.

Common modern reforms include: Henan traditional 16-stringed zheng, Guangdong traditional 16-stringed zheng, Shanghai 21-stringed zheng, Guangzhou 18-stringed zheng and 21-stringed zheng, Suzhou 21-stringed zheng and Beijing 21-stringed zheng. These zheng are transposition zheng or butterfly zheng. The main structure is shown in "Fig. 4".

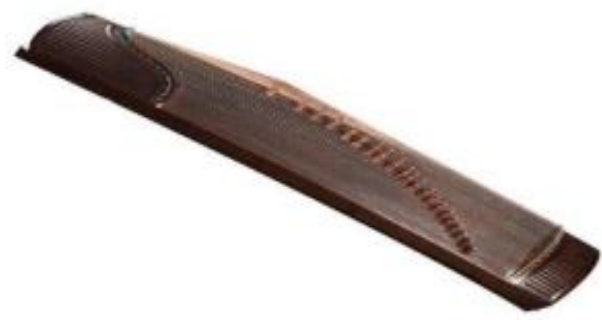

Fig. 4. Zheng.

1) Modulation zheng: The modulation zheng inherits the characteristics and performance techniques of the traditional guzheng. The method of modulation is to divide the performance into two parts on the left and the right in the middle of the bridge, and then use the sliding to cut the strings, so that the modulation zheng technique has the traditional pentatonic scale and the modern heptachord. On the basis of retaining the traditional features of guzheng, it solves the problem of the difficulty of guzheng modulation, and can also take into account the chord sequence arrangement of the heptachord and the twelve-tone equal temperament, which is the biggest feature of the guzheng modulation. The modulation zheng is widely loved for its beautiful timbre, thick tone quality and loud volume. Experts praise it as the Oriental piano.

The improved parts of the modulation zheng mainly include:

- The strings are fixed on the head string hole and the tail string hole on both sides of the body;

- It fixes the bottom of the bridge on the surface with threads and nuts;

- The baffle is at the lower end of the diagonal slide at the top of the bridge;

- The sliding groove is in contact with the strings and installed on the pulley in the middle of the diagonal slide.

Nowadays, the improved forms of the main modulation zheng include the following:

- Yingkou's 15-stringed pedal modulation zheng and 21-stringed key modulation zheng: these two kinds of modulation zheng are very popular in the country, and their modulation function mainly depends on the use of pedal or handpressing mechanical accessories to change the tension of the strings, thereby changing the pitch. The pedal modulation zheng can change to twelve tunes, and the hand-pressing type is divided into two categories of changing to 5 tunes and changing to 12 tunes.

- The counterpoint of the zheng head presses the chopped string for modulation: this modulation zheng is developed by Guangzhou Conservatory of Music and Shantou Musical Instrument Factory. By pedaling the sound key, the ratchet pendulous reed transmission part performs separate movements according to the requirements of the change of inflexion (this movement includes "raising the semitone and lowering the semitone"). The separate movement of the transmission part further makes the part of counterpoint pressed load string pressed, so as to achieve the purpose of chopped string for inflexion and achieving rapid modulation.

- Suzhou's 26-stringed pedal chopped string modulation zheng: the zheng is developed by the Suzhou Folk Musical Instrument No. 1 Factory. Its modulation function relies on the pedal-type yueshan chopped string modulation. The main functional principle is that part of the position of front yueshan changes due to the movement of the pedal.

- Frame-shift pedal modulation zheng: Shenyang Conservatory of Music developed this kind of 
zheng, which mainly uses pedal frame-shift for modulation

- Fret chopped string modulation zheng: Suzhou Folk Musical Instrument No. 1 Factory is the developer of this type of zheng. The realization of the modulation is to set the semitone fret within each effective string length, and use the string hook to press the string above the fret to achieve the purpose of modulation.

2) Butterfly zheng: The Shanghai Conservatory of Music developed the butterfly piano, named after its appearance like a butterfly. Its body shape design resembles two zheng that are joined together and adopt a resonance body. It is equipped with a string hook used to change the pitch of certain tuning tone, and it also adds a semitone or altered tone between certain chordal distance of the pentatonic scale tuning.

\section{PRoblems AND THOUghtS ON THE DEVELOPMENT OF CHINESE NATIONAL IMPROVED MUSICAL INSTRUMENTS}

\section{A. Problems in the development of Chinese national improved musical instruments}

In modern times, with the rise of Western musical instruments in China, the living space of many Chinese national musical instruments has been squeezed. In order to explore the future development direction of Chinese national musical instruments, many musical instrument makers and players have made various improvements. There are three main ideas: complete Westernization, integration of Chinese and Western, and adherence to tradition. These kinds of ideas more or less have their own drawbacks. Complete Westernization makes national musical instruments lose their own characteristics, the combination of Chinese and Western is sometimes neither fish nor fowl, and adherence to tradition will also gradually fade the national musical instruments from the mainstream.

Chinese plucked stringed orchestras are far less popular than Western orchestras. In recent years, most of the improvements of various national musical instruments have increased the volume and are in the direction of integration with "electricity" and "apparatus". The country is also paying more and more attention to the development of national musical instruments, but the direction of improvement still needs to be discussed.

\section{B. Thoughts on the development of Chinese national improved musical instruments}

Everything in the world is constantly changing and developing. Social progress has promoted the reform of national musical instruments. Reforms must be innovative in order to survive. But this innovation must meet the following four conditions:

1) Keeping ethnic elements: The reason why the national musical instrument can be named "national" is because it was born or changed here, and it has been marked with the national brand. If the ethnic element is removed, it can only be called a musical instrument, not a national musical instrument. For example, if the horse head string instrument has no "horse head", it will lose its distinctive national characteristics.

2) Being in line with national aesthetics: The improvement of national musical instruments should be based on the aesthetics of the Chinese people, rather than blindly catering to the international mainstream. Only improvements that conform to their own national aesthetics are truly suitable for the improvement of national musical instruments.

3) Maintaining the national charm: The national personality in the performance is the soul of the national musical instrument. The "White Snow in Sunny Spring" in the Western-style concert hall may be neither fish nor fowl in the performance with Chinese national musical instruments.

4) Combining art with science: Science is the primary productive force, and it is no exception in the improvement of national musical instruments. What material back panel can best show the expressive power of the instrument can be measured by scientific experimental data. Therefore, combining technology with art is a direction worth trying.

\section{Conclusion}

This paper aims to explore the possible directions of improving the living space of national musical instruments in modern times through the improvement of typical modern national musical instruments. It puts forward: to retain the national elements; fit the national aesthetics; maintain the national charm; combine art with science and other improved principles, so as to provide good ideas for the subsequent improvement of national musical instruments.

\section{References}

[1] Yi Jinxin. Research on contemporary national musica instruments reform process and reform countermeasures [J]. The Artist, 2020-02-01. (in Chinese)

[2] Wenyin. On the reform of Chinese national musical instruments [J]. Chinese Music, 1981(04):43-45. (in Chinese)

[3] He Lili. A textual research on three-stringed liuqin and fourstringed liuqin [J]. Musical Instruments, 2005(08):66-67. (in Chinese)

[4] Han Baoqiang. Chinese improved national musical instruments — plucked stringed instruments [J]. Entertainment Technology, 2006(05):74-78. (in Chinese) 
[5] Ai Ying, Feng Lei. The development process and thinking of the improvement of Chinese national musical instruments in the 20th century [J]. Northern Music, 2018,38(06):1-2. (in Chinese)

[6] Han Baoqiang. Improvement and prospect of Chinese national musical instruments [J]. Entertainment Technology, 2019(01):57-60. (in Chinese)

[7] Luo Jiaqi, Tang Heng. Inheritance and development of Chinese national musical instruments [J]. Frontier 2013-04-01. (in Chinese) 